\title{
Relationship between Occupational Stress, Coping Strategies and Job Satisfaction among Nurses working in General Hospitals and Psychiatric Hospitals
}

\author{
Shridhar. C Kulakarni ${ }^{1}$, Srimathi N. L ${ }^{2}$
}

\section{ABSTRACT}

The purpose of this research was to study the relationship between occupational stress, coping strategies and job satisfaction among nurses working in general hospital and psychiatric hospital. The sample consisted of 300 nurses (150 nurses from general hospital and 150 from psychiatric hospital) drawn from Hubli and Dharawad district hospitals, Chitradurga, Shimoga district hospitals of Karnataka. The primary objective of the study is to study the relationship between occupational stress, coping strategies and level of job satisfaction among nurses working in general hospitals and psychiatric hospitals. The participants were administered the occupational stress index developed by Prof. S. K. Srivastava and Prof. A. P. Singh, ways of coping questionnaire developed by Lazarus and Folkman (1989) and Job satisfaction questionnaire developed by C.N. Daftuar. The data were analyzed by using Pearson Product Moment Method of correlation to find out the relationship between these variables. The results of the study have shown that there is a significant positive relationship exists between the occupational stress, coping strategies and job satisfaction among nurses working in general and psychiatric hospitals.

Keywords: Occupational stress, Coping strategies, Job satisfaction and Nurses

Nursing is for the most part seen as stressful and demanding profession. It is both physically and mentally challenging. There is significant proof that nursing is a stressful occupation, which can prompt interruptions in both psychological and physical wellbeing and can disable professional practice:

Stress is a pervasive and tricky piece of daily life and in the workplace. It is a typical topic in nursing.

\footnotetext{
${ }^{1}$ Research scholar, Department of Studies in Psychology, University of Mysore, India

${ }^{2}$ Professor, Department of Studies in Psychology, Manasagangotri University of Mysore, India

*Responding Author

Received: February 18, 2017; Revision Received: March 17, 2017; Accepted: March 23, 2017

(C) 2017 Kulakarni S, Srimathi N; licensee IJIP. This is an Open Access Research distributed under the terms of the Creative Commons Attribution License (www.creativecommons.org/licenses/by/2.0), which permits unrestricted use, distribution, and reproduction in any Medium, provided the original work is properly cited.
} 


\section{Relationship between Occupational Stress, Coping Strategies and Job Satisfaction among Nurses working in General Hospitals and Psychiatric Hospitals}

1. There is a developing collection of proof, which accept that health care providers especially nurses experience stress throughout their work. Word related stress is characterized as the destructive physical and emotional reactions that happen when the prerequisites of the employment don't coordinate the capacities, reactions, or need of the worker.

2. Work place stress or job stress is characterized as any normal for the occupation environment that represents a risk to the individual, either over the top requests or lacking supplies to address the issue and lead to rising tension in a man.

3. Occupational stress exists in all professions. But, nursing has all the earmarks of being especially upsetting. In are view of more than 100 occupations, utilizing stress rating scale to look at work weights, nursing had one of the most elevated scores among the administration occupations.

Sources of stress for nurses can be categorized into four zones: workload, pressure from the organizations, interpersonal communications, and professionalism. In reality it is uncommon that only one source of stress is actually present in the circumstances. Sources of stress are much of the time interrelated and synergistic impacts are seen because of many of sources of stress. For instance, interpersonal conflicts might be because of organizational and administration issues. Recent studies have exhibited that Sources of work related stress among medical nurses fluctuate between regions, nations, organizations, divisions, nursing specialties and people. This has been credited to the diverse health systems, their culture, availability of resources, nature of work, distinctive educational levels, age, business contract, work experience and personality attributes (Lee and Wang, 2002; Lindholm, 2006; Peterson and Wilson, 2002).

\section{Coping Strategies:}

In terms of experience, Auerbach and Gramling (1998) found that coping skill is particularly an element of past experience, Kahn and Cooper (1993); concerning level, Syme (1975) has found that stress illness rates increased as people moved over the social level comparable with their educational level. The better educated and invested a man is, the less stress he feels (Sutherland and Cooper, 1990).

- $\quad$ One-fourth of workers view their jobs as the main stressor in their lives.

- $\quad$ Three-fourths of workers' trust the worker has more on-the job stress than an era back.

- $\quad$ Problems at work are all the more emphatically connected with health complaints than are some other life stressor-more so than even financial issues or family issues.

Epidemiologist Bengtet al, (2001) (University of Uppsala, Sweden) have been studying work related stress for 20 years says, that in Sweden stress among doctors is such an extent that their mental vitality has diminished and intellectual exhaustion(burnout)increased to critical levels. 


\section{Relationship between Occupational Stress, Coping Strategies and Job Satisfaction among Nurses working in General Hospitals and Psychiatric Hospitals}

Robert Karasek (1979) says "How much control a person has over his work is significant on the grounds that it influences how well he adapts to the demands of his employment”.

\section{Job Satisfaction}

Job satisfaction is characterized as the level or degree to which employees like their works (Spector, 1997). Various segments of job satisfaction have been distinguished counting incorporating satisfaction with pay, potential for innovativeness, self-sufficiency, assignment personality, satisfaction with organizational promotion approach and their individual promotions, satisfaction with associates, and accessible proceeding with education openings. Past researchers have revealed a reverse or negative relationship between perceived stress and job satisfaction, that is, as job satisfaction increases, stress decreases (Sveinsdottir, et al., 2006; Zangaro and Soeken, 2007).

Job Satisfaction is an affective orientation that a worker has towards their work (Price, 2001). What makes a job fulfilling or uninspiring does not depend just on the nature of the occupation, additionally on the desires that people have of what their employment ought to give (Spector, 1997). Most published research from different nations shows that job satisfaction is a noteworthy indicator of nursing absenteeism, burnout, turnover and intention to quit (Cavanagh, 1990, Siu 2002, Yin and Yang 2002.). Thus recognizable proof of the components identified with job satisfaction and investigation of their consequences for job satisfaction can possibly help the development of employment strategies to enhance maintenance and decrease turnover.

\section{Objective Of The Study:}

- To study the inter-relationship between occupational stress, job satisfaction and coping strategies

\section{Hypothesis Of The Study:}

- There will be a significant relationship exists between occupational stress, job satisfaction and coping strategies.

\section{Tools Used:}

\section{Demographic data sheet}

A semi structured questionnaire developed by the researcher was administered to the selected sample to collect the necessary information such as, the participant's name, gender, age, class, religion, education level socio-economic status etc.,

\section{Occupational Stress Index (OSI):}

Occupational Stress Index (OSI) was used to measure occupational stress of nurses prepared by Prof. S. K. Srivastava and Prof. A. P. Singh of Department of Psychology, Banaras Hindu University, Varanasi. This standardized questionnaire has the reliability coefficient ascertained 


\section{Relationship between Occupational Stress, Coping Strategies and Job Satisfaction among Nurses working in General Hospitals and Psychiatric Hospitals}

by Split half (odd-even) method and Cronbach's alpha- coefficient for the scale as a whole were found to be 0.937 and 0.90 respectively.

\section{Coping Checklist:}

Coping checklist was developed by Lazarus and Folkman(1989). The purpose of this checklist is to find out how people deal with or handle difficult situations that they have to face in their everyday life. The list provides some of the common used methods for handling stress and reducing stress. This scale aims at identifying preventive strategies for suicide prevention. Most of the suicides are impulsive at the stress situations. These situations are overcome through different coping patterns that are used consciously or unconsciously by everybody but sometimes it is difficult to develop a pattern of coping. Those coping methods by which they found some relief or solution to their problems are identified. There are 66 items, each statement you are using or not in stressful situation that indicates Not Used, Used Somewhat, Used Quite A Bit and Used a Great Deal.

Whether, each method is used or not in stressful situation is indicated as yes or no. It covers a wide range of cognitive, behavioral and emotional responses that are used to handle stress. There are eight subscales: confrontive coping, distancing, self controlling, seeking social support, accepting responsibility, escape avoidance, painful problem solving and positive reappraisal. Space is provided for providing their responses for each type of coping items.

\section{Job satisfaction scale.}

Job Satisfaction Scale developed by C.N. Daftuar consisting of 19 items including 2 which measure separately overall satisfaction with the company and overall satisfaction with the work was used for the purpose. The respondents were asked to rate each statement on a five point scale ranging from 5 (strongly agree) to 1 (strongly disagree).

The subject is asked after good rapport formation to attempt answering all statements. They were asked to give their responses on five point scale from strongly agree to strongly disagree. Instructions are printed on the cover page of the test booklet. It is good to reinforce instructions by orally reiterating that the examinee will be doing himself and must be good by being frank and honest in describing himself. In the present study all the subjects were literate. So they can read instructions easily.

Scale with the range of strongly agree to strongly disagree responses which are scored 5 to 1 and summed, the possible range of score was between 19 and 95. Higher score naturally indicates a higher level of job satisfaction.

\section{Procedure}

A total of 300 participants were selected for this study. They were drawn from different government general hospitals $(\mathrm{N}=150)$ and psychiatric hospitals $(\mathrm{N}=150)$ across Karnataka state.

(c) The International Journal of Indian Psychology, ISSN 2348-5396 (e) | ISSN: 2349-3429 (p) | 69 


\section{Relationship between Occupational Stress, Coping Strategies and Job Satisfaction among Nurses working in General Hospitals and Psychiatric Hospitals}

Initially the investigator established rapport with the authorities and employees and taken consent for their involvement in the proposed research. They were briefed about their participation and requested to fill up the bilingual research instruments under study. They were administered Ways of Coping and Job satisfaction questionnaires. During the process of administering the research questionnaires doubts were clarified.

After the data gathered from the participants, scoring was done according to the norms developed by the authors of the questionnaires. Later, the researcher found the relationship between occupational stress, coping strategies and job satisfaction of nurses who are working in the general and psychiatric settings.

\section{Data Analysis:}

The obtained data were scrutinized, scored according to the scoring keys respectively and subjected to the following statistical techniques to find out the relationship between the variables. - $\quad$ The correlation between occupational stress, coping strategies and job satisfaction was found out by using Pearson's Product Moment Correlation.

\section{RESULT ANALYSIS}

The data gathered from the participants about their level of occupational stress, coping strategies and job satisfaction are analyzed to find out the inter relationship between these variables. The following section of this chapter reveals the relationship between the variables of the present study.

\section{Table 1. Correlation between the variables}

\begin{tabular}{|c|c|c|c|c|c|c|c|c|c|c|}
\hline \multicolumn{11}{|c|}{ Variable 2} \\
\hline & 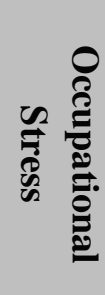 & 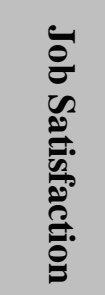 & 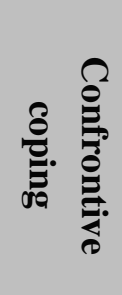 & 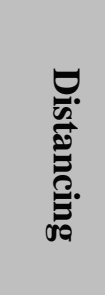 & 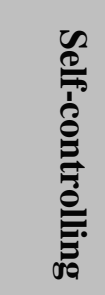 & 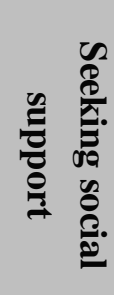 & 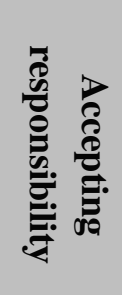 & 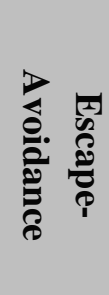 & 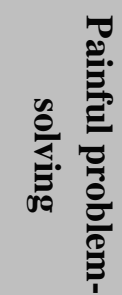 & 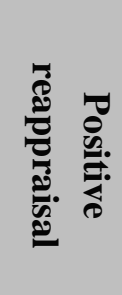 \\
\hline \multirow{2}{*}{$\begin{array}{c}\text { Occupational } \\
\text { Stress }\end{array}$} & & .248 & .271 & .316 & .418 & .194 & .214 & .393 & .312 & .366 \\
\hline & & $.001^{* *}$ & $.001^{* *}$ & $.001^{* *}$ & $.001^{*+}$ & $.001^{* *}$ & $.001^{* *}$ & $.001^{* *}$ & $.001^{* *}$ & $.001^{* *}$ \\
\hline \multirow{2}{*}{$\begin{array}{c}\text { Job } \\
\text { Satisfaction }\end{array}$} & & & .330 & .272 & .316 & .384 & .223 & .154 & .404 & .460 \\
\hline & & & $.001^{* *}$ & $.001^{* *}$ & $.001^{* *}$ & $.001^{* *}$ & $.001^{* *}$ & $.007^{* *}$ & $.001^{* *}$ & $.001^{* *}$ \\
\hline
\end{tabular}




\section{Relationship between Occupational Stress, Coping Strategies and Job Satisfaction among Nurses working in General Hospitals and Psychiatric Hospitals}

*significant @0.05,**significant @ 0.01As shown in table 4.4, occupational stress has a significant positive relationship with job satisfaction $(\mathrm{r}=0.248, \mathrm{p}=0.001<0.01)$ and different coping strategies, such as confrontive coping $(\mathrm{r}=.271, \mathrm{p}=.001<.01)$, Distancing coping $(\mathrm{r}=$ $.316, \mathrm{p}=.001<.01)$, self controlling coping $(\mathrm{r}=.418, \mathrm{p}=.001<.01)$, seeking social support coping $(\mathrm{r}=.194, \mathrm{p}=.001<.01)$,accepting responsibility coping $(\mathrm{r}=.214, \mathrm{p}=.001<.01)$, escape avoidance coping $(\mathrm{r}=.393, \mathrm{p}=.001<.01)$, planful problem solving coping $(\mathrm{r}=.312, \mathrm{p}=$ $.001<.01)$ and positive reappraisal coping $(\mathrm{r}=.366, \mathrm{p}=.001<.01)$. The present study also reveals that job satisfaction also has a significant positive relationship with different coping strategies. Such as confrontive coping $(\mathrm{r}=.330, \mathrm{p}=.001<.01)$, Distancing coping $(\mathrm{r}=.272, \mathrm{p}=$ $.001<.01)$, self controlling coping $(\mathrm{r}=.316, \mathrm{p}=.001<.01)$, seeking social support coping $(\mathrm{r}=$ $.384, \mathrm{p}=.001<.01)$,accepting responsibility coping $(\mathrm{r}=.223, \mathrm{p}=.001<.01)$, escape avoidance coping $(\mathrm{r}=.154, \mathrm{p}=.007<.01)$, planful problem solving coping $(\mathrm{r}=.404, \mathrm{p}=.001<.01)$ and positive reappraisal coping $(\mathrm{r}=.460, \mathrm{p}=.001<.01)$.

\section{DISCUSSION}

One of the main objectives of the study is to find out the relationship between occupational stress, job satisfaction and coping strategies. This hypothesis was formulated based on the entire population's results which have been taken for the study states that 'There will be significant relationship exists between occupational stress, job satisfaction and coping strategies'. The findings of the study revealed that the relationship between occupational stress and job satisfaction. It has been indicated that occupational stress has a significant positive relationship with job satisfaction. It shows that when there is an increase in occupational stress it gradually reduces the job satisfaction among the nurses. Because, the situation which increases occupational stress affect negatively on performance of the workers in the workplace and finally reduces the level of performance and job satisfaction in the workers. On the other hand, when there is a decrease in occupational stress it increases the job performance and job satisfaction. Some of the factors in occupational stress which affect on job satisfaction of the nurses are Role Overload, Role Conflict, under participation, Powerlessness, Intrinsic impoverishment, Unprofitability, Role ambiguity, Unreasonable group \& Political pressures, Responsibility for persons, Poor peer Relations, Low status and Strenuous working conditions.

The results also shown that occupational stress has significant positive relationship with coping strategies. The statistical analysis of Pearson Product moment method has revealed each of the coping strategies are significantly positively correlated with occupational stress. The relationship between occupational stress and Confrontive coping indicates that when there is an increase in occupational stress the nurse are not able to use Confrontive coping in the problematic situations of stressful conditions. They may not be able to take proper actions and confront with the problems. On the other hand, when there is decrease in occupational stress they may take proper actions to confront with the problem. 


\section{Relationship between Occupational Stress, Coping Strategies and Job Satisfaction among Nurses working in General Hospitals and Psychiatric Hospitals}

Another coping strategy distancing which is a passive coping strategy also has a significant positive relationship with the occupational stress. It indicates that when the nurses face stressful situations they may always think that the problem solves itself without their effort and they detach from the situation in the presence of high level occupational stress. When the level occupational stress in decreased they may not use distancing coping instead they use other coping strategies which would be helpful for them to solve problems or reducing stress.

The passive coping strategy self-controlling also has a significant positive relationship with occupational stress. It has been said that when the nurses face stressful situations they may always make good and important efforts to regulate their feelings and actions to face the situation or sole the problem when the level of occupational stress is low. When the level occupational stress in increased they may not use self-supporting coping instead they use other coping strategies.

Seeking social support is another coping strategy which is active coping method also has a significant positive relationship with the occupational stress. It indicates that then the level of occupational stress is low, the nurses use this coping strategy in resolving the problems which have been raised in the working situations. They seek informational and social support from the other employees in resolving their problems. If the level of occupational stress is high in nurses they may not seek informational or emotional support from fellow employees in resolving their problems.

The coping strategy of accepting responsibility also has significant positive relationship with occupational stress. It can be noted that an increase in occupational stress avoid the use of coping strategy of accepting responsibility in nurses. They may not accepting their role in the problem which have been raised in the working conditions. When there is low in occupational stress they accept their role raising the problems and try to solve by using the available resources.

Another coping strategy escape avoidance coping has a significant positive relationship with the occupational stress. In indicates that when the nurses experience high level of occupational stress, most of the times they use escape avoidance coping in stressful situations or problematic conditions. It indicates that they try to avoid the situations where the problems arises. They don't even think of the consequences of the situations they face or confront. When there is low level of occupational stress the nurses use adaptive coping strategies to resolve their problems instead of escaping from the situations.

Painful problem solving is another active coping strategy. It indicates that in the stressful situations or problematic conditions people try to use the available resources and execute appropriate solution methods for resolving the issues. This coping strategy also has positive 


\section{Relationship between Occupational Stress, Coping Strategies and Job Satisfaction among Nurses working in General Hospitals and Psychiatric Hospitals}

relationship with the occupational stress. It has been said that when there is low level of occupational stress nurses use the available resources and try to solve their own problems by executing the appropriate strategies. But when there is high level of occupational stress they use escape avoidance coping most of the times.

The last coping strategy positive reappraisal also has a significant positive relationship with the occupational stress. In the presence of high level of occupational stress nurses fail to use positive reappraisal coping in the strenuous working conditions. Positive reappraisal basically tells that people try to create positive meaning and focus on their personal growth. When they confront with any problems they try to find a meaning in resolving the problem by using the available resources and they focus on their personal career growth. If they have low level of occupational stress they can find a meaning in resolving the problems and they can focus on their personal career growth or development.

Another important variable which has been taken for this present study is job satisfaction, which also has a significant positive relationship with the coping strategies.

The results also shown that job satisfaction has significant positive relationship with coping strategies. The statistical analysis of Pearson Product moment method has revealed each of the coping strategies are significantly positively correlated with job satisfaction. The relationship between job satisfaction and Confrontive coping indicates that when there is low level of job satisfaction the nurse are not able to use Confrontive coping in the problematic situations of stressful conditions. They may not be able to take proper actions and confront with the problems. On the other hand, when there is high level of job satisfaction they may take proper actions to confront with the problem and their performance in the work also can be increased.

Another coping strategy distancing which is a passive coping strategy also has a significant positive relationship with the job satisfaction. It indicates that when the nurses experience satisfaction about their work they may always think that the problem solves itself without their effort and they detach from the situation in the presence of low level job satisfaction. When the level job satisfaction in high they may not use distancing coping instead they use other coping strategies and their performance in the work also can be increased.

The passive coping strategy self-controlling also has a significant positive relationship with job satisfaction. It has been said that when the nurses feel satisfaction about their jobs they may always make good and important efforts to regulate their feelings and actions to face the situation or solve the problem and increasing in their job performance can also be found. When the level of job dissatisfaction is low they may not use self-supporting coping, instead they use other coping strategies. 


\section{Relationship between Occupational Stress, Coping Strategies and Job Satisfaction among Nurses working in General Hospitals and Psychiatric Hospitals}

Seeking social support is another coping strategy which is active coping method also has a significant positive relationship with the job dissatisfaction. It indicates that then the level of job dissatisfaction is high, the nurses use this coping strategy in resolving the problems which have been raised in the working situations and their performance in the work also can be increased. They seek informational and social support from the other employees in resolving their problems. If the level of job dissatisfaction is low in nurses they may not seek informational or emotional support from fellow employees in resolving their problems and it also affects negatively in their job performance.

The coping strategy of accepting responsibility also has significant positive relationship with job dissatisfaction. It can be noted that a decrease in level of job dissatisfaction avoid the use of coping strategy of accepting responsibility in nurses. They may not accepting their role in the problem which have been raised in the working conditions. When there is high level of job dissatisfaction they accept their role raising the problems and try to solve by using the available resources and their performance in the work also can be increased.

Another coping strategy escape avoidance coping has a significant positive relationship with the job dissatisfaction. In indicates that when the nurses experience low level of job dissatisfaction, most of the times they use escape avoidance coping in stressful situations or problematic conditions. It indicates that they try to avoid the situations where the problems arise. They don't even think of the consequences of the situations they face or confront and it also affects negatively on their performance. When there is high level of job dissatisfaction the nurses use adaptive coping strategies to resolve their problems instead of escaping from the situations and their performance in the work also can be increased.

Painful problem solving is another active coping strategy. It indicates that in the stressful situations or problematic conditions people try to use the available resources and execute appropriate solution methods for resolving the issues. This coping strategy also has positive relationship with the occupational stress. It has been said that when there is high level of job satisfaction, nurses use the available resources and try to solve their own problems by executing the appropriate strategies and they may show better performance in their work. But when there is low level of job satisfaction they use escape avoidance coping most of the times and their performance in the work also can be decreased.

The last coping strategy positive reappraisal also has a significant positive relationship with the job satisfaction. In the presence of high level of job satisfaction nurses fail to use positive reappraisal coping in the strenuous working conditions. Positive reappraisal basically tells that people try to create positive meaning and focus on their personal growth. When they confront with any problems they try to find a meaning in resolving the problem by using the available 


\section{Relationship between Occupational Stress, Coping Strategies and Job Satisfaction among Nurses working in General Hospitals and Psychiatric Hospitals}

resources and they focus on their personal career growth. If they have low level of job satisfaction they may not able to find a meaning in resolving the problems and they can focus on their personal career growth or development and their performance would be gone down.

\section{CONCLUSION}

Nursing profession is the most challenging job in the present context. In this context lot of factors will affect the nature of work of the nurses. In which occupational stress is the most important one which will affect negatively on nurses working performance. The present study was tried to explore the relationship between occupational stress, coping strategies and job satisfaction among general hospital nurses and Psychiatric hospital nurses. It has been said that the occupational stress they experience in the organizational settings, coping strategies they use in the reduction of occupational stress or problems and the level of job satisfaction they experience in the work they do influence each other and significant positive relationship has shown.

\section{Acknowledgments}

The author appreciates all those who participated in the study and helped to facilitate the research process.

\section{Conflict of Interests}

The author declared no conflict of interests.

\section{REFERENCES}

Auerbach, S. M., \&Gramling, S. E. (1998). Stress management: Psychological foundations. Upper Saddle River, NJ: Prentice Hall.

Bennett, P., Lowe, R., Matthews, V., Dourali, M., \& Tattersall, A. (2001). Stress in nurses: coping, managerial support and work demand. Stress \& Health: Journal of the International Society for the Investigation of Stress, 17(1), 55- 63.

Cavanagh S. (1990) Predictors of nursing staff turnover. Journal of Advanced Nursing. 1990;15(3):373-80.

Kahn, W.A. (1993), "Caring for the caregivers: patterns of organizational caregiving", Administrative Science Quarterly, Vol. 38 No. 4, pp. 539-64.

Karasek, R. A. (1979). Job demands, job decision latitude, and mental strain: Implications for job re-design. Administrative Science Quarterly., 24(2), 285- 308.

Lee, I., \& Wang, H. (2002). Perceived Occupational Stress and Related factors in Public Health Nurses. Journal of Nursing Research, 10(4), 253-259.

Lindholm, M. (2006). Working conditions, psychosocial resources and work stress in nurses and physicians in chief managers positions. Journal of Nursing Management, 14(4), 300-309. 


\section{Relationship between Occupational Stress, Coping Strategies and Job Satisfaction among Nurses working in General Hospitals and Psychiatric Hospitals}

Peterson, M., \& Wilson, J. F. (2002). The culture-work-health model and work stress. American Journal of Health Behavior, 26 (1), 16-24.

Price JL , (2001) Reflections on the determinants of voluntary turnover. International Journal of Manpower. 2001; 22(7): 600-624.

Siu OL. (2002) Predictors of job satisfaction and absenteeism in two samples of Hong Kong nurses. Journal of Advanced Nursing. 2002; 4(2):218-29.

Spector, P., E. (1997). Job Satisfaction Application, Assessment, Cause, and Consequences. California: Thousand Oaks: Sage Publications.

Sveinsdóttir H. (2006) Self-assessed quality of sleep, occupational health, working environment, illness experience and job satisfaction of female nurses working different combination of shifts. Scandinavian Journal of Caring Sciences. June;20(2)229-37.

Yang SM, Shung PM, Yang M. Job strain and minor psychiatric morbidity among hospital nurses in southern Taiwan. Psychiatry and Clinical Neurosciences.2004 December; 58 (6): 63641.

Zangaro, G. A., \& Soeken, K. L. (2007). A Meta-Analysis of studies of Nurses’ job satisfaction. Research in Nursing and Health, 30, 445-458.

How to cite this article: Kulakarni S, Srimathi N (2017), Relationship between Occupational Stress, Coping Strategies and Job Satisfaction among Nurses working in General Hospitals and Psychiatric Hospitals, International Journal of Indian Psychology, Volume 4, Issue 2, No. 94, ISSN:2348-5396 (e), ISSN:2349-3429 (p), DIP:18.01.147/20170402, ISBN:978-1-365-84229-0 